\title{
A traumatized melanocytic nevus with atypical clinical and dermoscopic features: a case report and review of the literature
}

\author{
Maruša Selan ${ }^{1}$, Daja Šekoranja², Mateja Starbek Zorko ${ }^{1,3}$ 凶 \\ ${ }^{1}$ Department of Dermatovenerology, Ljubljana University Medical Center, Ljubljana, Slovenia. ${ }^{2}$ Institute of Pathology, Faculty of Medicine, University of
} Ljubljana, Ljubljana, Slovenia. ${ }^{3}$ Faculty of Medicine, University of Ljubljana, Ljubljana, Slovenia.

\begin{abstract}
We report the case of an adolescent girl that presented with an atypical melanocytic lesion on the left gluteal region, suspicious for melanoma. She was healthy with no associated diseases, and there was no history of skin cancer in the family. The nevus had been present for several years, but she had noted a change and growth of it in the last few months. She reported that the nevus was injured about 2 years earlier and it had appeared different ever since. Although dermoscopic examination showed the lesion to be highly suspicious for melanoma and it was therefore surgically excised on the same day, pathohistological examination showed a compound melanocytic nevus with extensive dermal fibrosis/regression and overlying atypical junctional hyperplasia of melanocytes consistent with pseudomelanoma, also known as recurrent melanocytic nevus.
\end{abstract}

Keywords: melanoma mimic, melanoma, traumatized melanocytic nevus, compound melanocytic nevus

Received: 11 February 2021 | Returned for modification: 27 February 2021 | Accepted: 3 March 2021

\section{Case report}

A 17-year-old girl was referred to our outpatient clinic due to a change in a melanocytic nevus on the left gluteus (Fig. 1). The nevus had been present on the left gluteal region for many years and it was partially raised above the surrounding skin, but change and growth had been noticed in the preceding few months. She reported that the nevus had been injured approximately 2 years earlier, and it had appeared different in shape ever since. On examination, a $12 \mathrm{~mm}$, unevenly pigmented, black and brown macula was observed. Detailed dermoscopy revealed two hyperpigmented areas on the medial pole, one with suspected regression. Brown hyperpigmentation was present at the edge (Fig. 2). The girl was otherwise healthy, without associated diseases. Her family history was negative for skin cancer. Following the guidelines, due to the highly suspicious lesion for melanoma, we referred her for excision and the tissue was sent for pathohistological examination. Histological examination showed a compound melanocytic nevus with extensive dermal fibrosis/regression and overlying atypical junctional hyperplasia of melanocytes consistent with pseudomelanoma (Fig. 3). Immunohistochemistry for p16 showed mosaic positivity throughout the lesion.

\section{Discussion}

Traumatic events on benign nevi and their consequences have been an ongoing topic of discussion and research. There is a common misbelief among patients that trauma to an otherwise benign nevus is somehow dangerous, potentially leading to transformation of a benign nevus to melanoma formation, causing a great deal of concern and stress among patients. On the other hand, because trauma can change the morphology of a nevus, dermoscopic evaluation of a nevus after trauma can be difficult even for an experienced dermatologist. Likewise, certain histological features common in traumatized nevi may render histological interpretation difficult and lead to an overdiagnosis of melanoma, especially if appropriate clinical data (i.e., history of trauma or previous procedure) are unavailable (1).

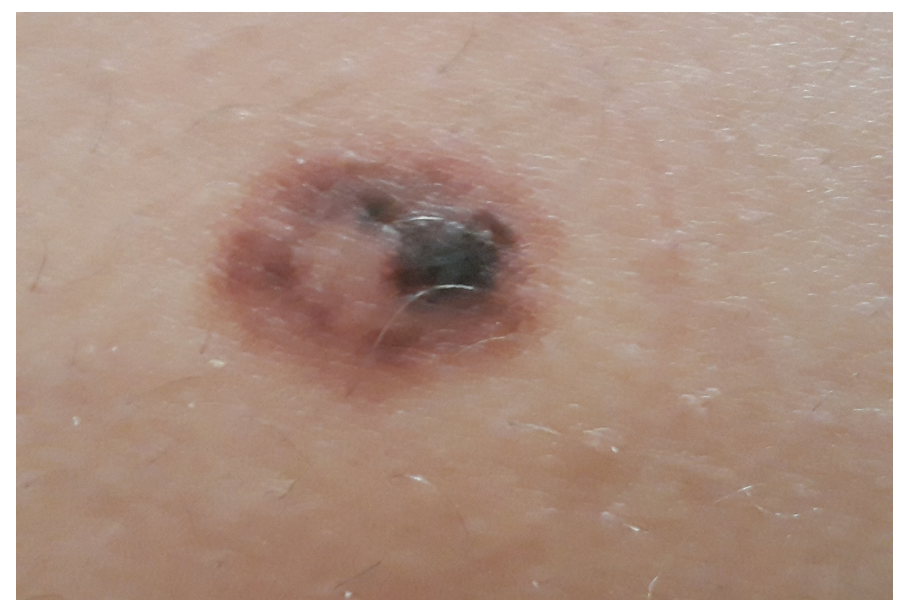

Figure 1 | A 17-year-old girl with unevenly pigmented black and brown macula on the left gluteal region.

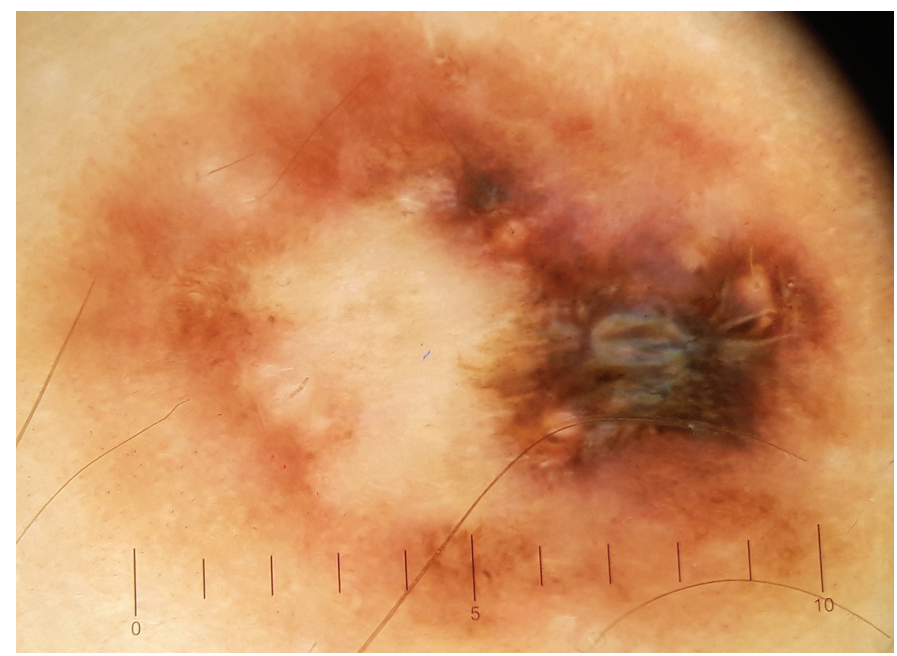

Figure $2 \mid$ A dermoscopic image of the suspected nevus. 


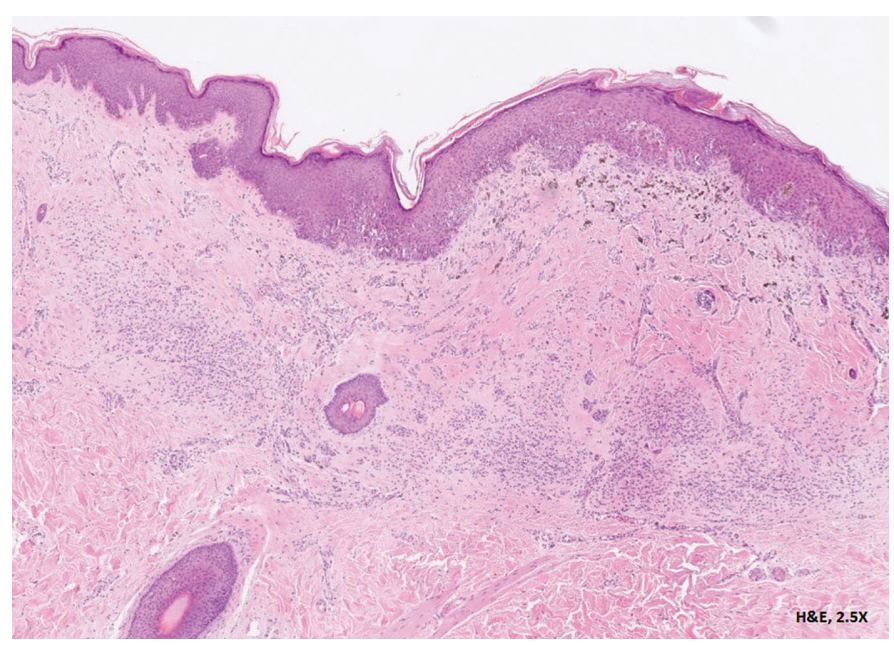

Figure 3 | Low-power view of compound melanocytic nevus, with superficial dermal fibrosis consistent with previous trauma, clinically confirmed (H\&E 2.5×).

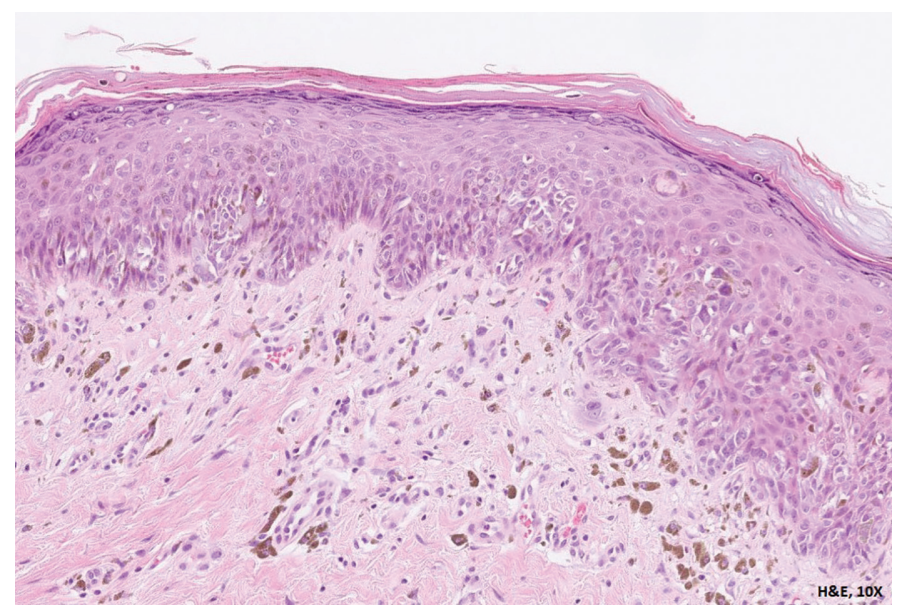

Figure 4 | Intraepidermal melanocytes (in the area above dermal fibrosis with pigment incontinence) exhibit epithelioid morphology with mild cytologic atypia and focal pagetoid spread (H\&E 10x).

The relationship between melanoma and trauma to a preexisting nevus was first studied in 1913 by Gaskill (2). Later, several more authors wrote about the topic, and one study, published in 1960, demonstrated that a single or repeated trauma failed to produce malignant melanocytic tumors in hamsters (3). Six years later, the same authors investigated this problem again, this time in hybrid fish, and the conclusion was the same (4). In 2000, Kaskel et al. investigated the link between traumatic events and melanoma development in a large study in which 369 cases of melanoma were reviewed, and they concluded that there is no evidence for trauma being the cause of melanoma formation (5). So far, based on research, there is no evidence for traumatic events to be causative factors for melanoma formation (2-5). Rather than causing melanoma, trauma is likely to be the reason a nevus attracts patients' attention and causes them to observe it more closely. With regular self-monitoring of nevi after trauma, a patient can also incidentally detect a newly formed melanoma that is not causally related to previous trauma of a nevus (5).

Dermoscopy is an essential tool for detecting melanoma because it reveals asymmetry before it becomes clinically evident. The most common suspicious findings suggesting melanoma are regression, an atypical network, and irregular dots/globules (6). The standard approach assumes that any clinically suspicious lesion should be surgically removed and histopathologically examined, especially if it undergoes changes in its clinical appearance in a short period of time (7). Melanoma is the sixth most frequently diagnosed cancer in men and women in Slovenia (8). Melanoma itself is aggressive and can be difficult to distinguish from a variety of benign melanocytic proliferations; for example, dysplastic nevi, Spitz nevi and their variants, pigmented spindle cell nevi, cellular blue nevi, deep penetrating nevi, acral nevi, and recurrent nevi (9). A recurrent nevus usually develops at the site of a previously (incompletely) excised nevus, most commonly a compound nevus. Development after accidental trauma, as seen in our case, chronic irritation, incomplete laser treatment, or application of topical agents is also common (10-12). The most common site is the back, and it is seen with higher prevalence in young female patients with dark skin $(7,13)$. Histologically, recurrent nevi are characterized by mildly to moderately atypical junctional melanocytes, in nests and singly, usually with epithelioid morphology and sometimes with pagetoid spread. These atypical features are essentially limited to the area above the dermal scar, whereas in the dermis under and next to the scar remnants of a previously excised nevus can sometimes be evident (14). Immunohistochemistry may be of limited use. p16 staining can be performed as a reliable surrogate marker for homozygous deletion of CDKN2A, which may be present in melanoma but never in a nevus (15). Focal or diffuse complete loss of p16 expression (being indicative of homozygous $\mathrm{CDKN} 2 \mathrm{~A}$ deletion) is therefore specific for melanoma, whereas retained p16 expression (either diffusely positive or mosaic expression, as in our case; Fig. 4) does not exclude it (15). In the end, clinicopathological correlation is often crucial in order to avoid overdiagnosis of melanoma (16).

Based on previous studies, past trauma to a nevus is not a reason for melanoma formation. Because a benign nevus after trauma is likely to become clinically suspicious, conservative complete excision is reasonable. Clinical information on prior trauma, laser therapy, or prior partial excision of benign nevi is crucial for a histopathologist to avoid overdiagnosis of melanoma, especially if recognition of the lesion is challenging.

\section{References}

1. Piccolo V, Russo T, Giacomel J, Lallas A, Alfano R, Argenziano G. Dispelling myths concerning pigmented skin lesions. J Eur Acad Dermatol Venereol. 2016;30:91925.

2. Gaskill HK. Melanotic sarcomas resulting from irritation of pigmented nevi. JAMA. 1913;60:341-4.

3. Ghadially FN, Illman O, Baker SF. The effect of trauma on the melanotic tumours of the hamster. Br J Cancer. 1960;14:467.

4. Ghadially FN. Trauma and melanoma production. Nature. 1966;211:1199.

5. Kaskel P, Kind P, Sander S, Peter RU, Krähn G. Trauma and melanoma formation: a true association? Br J Dermatol. 2000;143:749-53.

6. Lallas A, Longo C, Manfredini M, Benati E, Babino G, Chinazzo C, et al. Accuracy of dermoscopic criteria for the diagnosis of melanoma in situ. JAMA Dermatol. 2018;154:414-9.

7. Selim MA, Vollmer RT, Herman CM, Pham TT, Turner JW. Melanocytic nevi with nonsurgical trauma: a histopathologic study. Am J Dermatopathol. 2007;29: 134-6.

8. Zadnik V, Žagar T, Lokar K. Osnovni podatki o raku v Sloveniji. Epidemiologija in register raka [Internet]. Ljubljana: Onkološki inštitut Ljubljana; 2019. Available from: https://www.onko-i.si/fileadmin/onko/datoteke/dokumenti/RRS/ Rak_v_Sloveniji_2019.pdf. 
9. Bsirini C, Smoller RB. Histologic mimics of malignant melanoma. Singapore Med J. 2018;59:602-7.

10. Blessing K. Benign atypical nevi: diagnostic difficulties and continued controversy. Histopathology. 1999;34:189-98.

11. Grunwald MH, Gat A, Amichai B. Pseudomelanoma after Solcoderm treatment. Melanoma Res. 2006;16:459-60.

12. Lee HW, Ahn SJ, Lee MW, Choi JH, Moon KC, Koh JK. Pseudomelanoma following laser therapy. J Eur Acad Dermatol Venereol. 2006;20:342-4.

13. Heck R, Ferrari T, Cartell A, Bakos RM. Clinical and dermoscopic (in vivo and ex vivo) predictors of recurrent nevi. Eur J Dermatol. 2019;29:179-84
14. Luzar B, Bastian BC, North JP, Calonje E. Melanocytic nevi. In: Calonje E, Brenn T, Lazar AJ, Billings SD, editors. McKee's Pathology of the skin: with clinical correlations. Edinburgh: Elsevier; 2019. p. 1257-9.

15. Oaxaca G, Billings SD, Ko JS. p16 range of expression in dermal predominant benign epithelioid and spindled nevi and melanoma. J Cutan Pathol. 2020;47:81523.

16. Fox JC, Reed JA, Shea CR. The recurrent nevus phenomenon: a history of challenge, controversy, and discovery. Arch Pathol Lab Med. 2011;135:842-6. 